Revista Estudios, (39), 2019.

Diciembre 2018-Mayo 2019

ISSN 1659-3316

Salazar Horr Marlene

III Sección

Música, teatro y cine: medios y funciones

\title{
La Ruta de su Evasión Una ópera costarricense que le devuelve la voz a un violento silencio
}

\author{
Marlene Salazar Horr \\ Universidad de Costa Rica, Costa Rica \\ salazarhorr@gmail.com \\ https://orcid.org/0000-0001-8359-4112
}

Recibido: 1 de abril de 2019

Aceptado: 6 de agosto de 2019

Resumen: Este artículo es una reflexión que pretende acercarse al paisaje sonoro creado por la puesta en escena de la ópera costarricense La Ruta de su Evasión de Carlos José Castro en colaboración con Roxana Ávila Harper, del Teatro Abya Yala, estrenada el 1 de abril de 2017 y establecer posibles relaciones interdiscursivas entre ambos textos a partir de categorías tales como la voz y el silencio. Se reflexiona sobre la tensión y la violencia que produce el enfrentamiento entre el silencio y la voz, y como este construye múltiples entornos sonoros que se erigen por medio de otros elementos tales como la luz, el vestuario y la escenografía. Para desembocar en un discurso que rescata una realidad conscientemente acallada que atentó, en su momento, contra la identidad hegemónica.

Palabras clave: ópera costarricense; violencia; voz; silencio; paisaje sonoro.

\section{La Ruta de su Evasión A Costa Rican opera that returns the voice to a violent silence}

La Revista Estudios es editada por la Universidad de Costa Rica y se distribuye bajo una Licencia Creative Commons Atribución-NoComercial-CompartirIgual 3.0 Costa Rica. Para más información envíe un mensaje a 
Abstract: This article is a reflection that intends to approach the sound landscape created by the staging of the Costa Rican opera La Ruta de su Evasión by Carlos José Castro in collaboration with Roxana Ávila Harper of the Abya Yala Theater Released on April 1, 2017 and to establish possible interdiscursive relations between both texts from categories such as voice and silence. It reflects on the tension and violence produced by the confrontation between silence and voice, and how it builds multiple sound environments that are erected through other elements such as light, costumes and scenery. To end in a discourse that rescues a consciously silenced reality that, at the time, attempted against hegemonic identity.

Keywords: Costa Rican opera; violence; voice; silence; sound landscape.

\section{La Ruta de su Evasión Una ópera costarricense que le devuelve la voz a un violento silencio}

El jarrón da forma al vacío y la música al silencio Georges Braque

\section{Consideraciones preliminares}

La literatura costarricense se ha leído, durante mucho tiempo, desde el discurso de una identidad hegemónica. A partir de estos textos se ha buscado crear la "Gran Historia" de Costa Rica, y con ella una identidad inamovible que la inserte dentro del mundo, que la ubique en un lugar central. Esta visión ha anulado cualquier otra concepción de literatura que pueda emanar de nuestro país, ya que no se ajusta al proyecto identitario establecido por la institución literaria, de ahí que Yolanda Oreamuno Unger y su obra La ruta de su evasión, publicada en 1948, hayan sido silenciadas durante mucho tiempo. Si bien su obra ha sido retomada en espacios académicos, en la actualidad tiene un gran valor que se rompa el silencio que ha prevalecido en otros espacios, y especialmente, con voces de este medio costarricense, acompañadas por una música que se vincula con el espacio cercano, íntimo.

\section{(c) (i) (9) (2)}

La Revista Estudios es editada por la Universidad de Costa Rica y se distribuye bajo una Licencia Creative Commons Atribución-NoComercial-CompartirIgual 3.0 Costa Rica. Para más información envíe un mensaje a 
La ópera costarricense La ruta de su evasión del compositor Carlos José Castro presenta una interesante lectura de la novela homónima, pues reconstruye un contexto desde una mirada que fragmenta ese compacto imposible llamado construcción identitaria costarricense. El libreto escrito por Roxana Ávila y Carlos José Castro permite un acercamiento a los actantes de un texto que se dice y se desdice, en la medida que reconoce miradas, voces y discursos de unos y otros, desde el claroscuro del texto.

En la novela se aborda la realidad de una familia de clase media durante los años 40 y sus conflictivas relaciones son los elementos esenciales de la historia, la cual se entreteje alrededor de la figura de Teresa Mendoza como núcleo organizador de la acción y a través de sus ojos vemos al resto de los integrantes de esta familia. Ninguna de las figuras masculinas de esa casa es capaz de seguir los parámetros sociales establecidos para ser un "buen hombre", ese "tico" pacífico.

Teresa, por medio de escenas en retrospectiva, muestra ese fluir vital de su historia personal y familiar y cómo ese constructo que ella considera "su familia" se desmorona, ya que ese espacio denominado hogar es un espacio de vacío, de silencio. Finalmente, esto la lleva a aceptar el silencio último, la muerte. Estas escenas proyectan los conflictos internos en una familia costarricense durante la década de los 40 y permiten una mirada hacia un espacio silenciado por la crítica, pues la ambientan en México, a partir de lecturas biográficas del texto. Rima de Vallbona, estudiosa de la obra de Oreamuno, en su artículo El estigma del escritor (1972), indica que "Críticas acerbas llovieron contra su actitud revolucionaria y moderna, pero Yolanda Oreamuno, indiferente, continuó abriendo el camino a una nueva, rica y profunda literatura, en la que el hombre moderno iba a estar presente con sus inquietudes y circunstancias vitales." (p. 475).

Esta novela fue publicada en 1948 y ganó, ese mismo año, un premio en el Concurso Centroamericano de Novela convocado por el Ministerio de Educación Pública de Guatemala, sin embargo, ha caído en un largo silencio pues fue

\section{(c) (i) (2)}

La Revista Estudios es editada por la Universidad de Costa Rica y se distribuye bajo una Licencia Creative Commons Atribución-NoComercial-CompartirIgual 3.0 Costa Rica. Para más información envíe un mensaje a revistaestudios.eeg@ucr.ac.cr. 
editada nuevamente hasta 1970 por EDUCA. De ahí que los posteriores acercamientos al texto estén en función de lecturas sobre la identidad hegemónica mayormente o incluso sobre nociones de género, y no vayan más allá, hacia un verdadero cuestionamiento de la construcción de los individuos como seres en carencia, como individuos fragmentados. Esto con el fin de romper ese ideario costarricense que plantea a los costarricenses, frente a los otros, como modelos por seguir en un camino hacia la paz y los valores.

Por ejemplo, María Arrillaga en su artículo Atisbos Feministas en La Ruta de su evasión de Yolanda Oreamuno (1989) aborda la construcción de los personajes desde la teoría de género y establece elementos particulares en cada uno de los personajes. Para el caso de Esteban indica que "es feminista en la medida en que no solo es bondadoso y comprende a la mujer, sino que teoriza sobre su situación.” (p.48). De igual forma, Zapparoli y Núñez en su artículo El discurso patriarcal en La ruta de su evasión de Yolanda Oreamuno: una lectura de la otredad a través de la polifonía Bajtiniana (2007) se enfoca en el discurso patriarcal y la confrontación entre las voces masculinas y femeninas dentro del texto, pues afirman que "Las figuras femeninas están supeditadas a las masculinas como objetos construidos por el otro. Ellas están definidas y determinadas por la visión de los hombres" (p.15).

También, teóricos como Werner Mackenbach con su artículo YO o las trampas de la biografía (2007) han analizado acercamientos que se han hecho a este texto desde criterios tales como el biografismo, la novela de personaje, literatura femenina y geografía literaria. De ahí que Mackenbach afirme que

"Muchos de los estudios mencionados que se dedican al análisis de las formas y estructuras literarias de la novela de Oreamuno se han ocupado ampliamente del estudio de estos elementos innovadores en el contexto de la literatura costarricense de su época (especialmente Picado Gómez 1979: 31-101; Robles Mohs 1988; Macaya 1997: 135-182; y también Urbano

\section{(C) $(0)$}

La Revista Estudios es editada por la Universidad de Costa Rica y se distribuye bajo una Licencia Creative Commons Atribución-NoComercial-CompartirIgual 3.0 Costa Rica. Para más información envíe un mensaje a revistaestudios.eeg@ucr.ac.cr. 
ISSN 1659-3316 Salazar Horr Marlene 1968: 160-185; Vallbona 2006: 59- 73). Sin embargo, en este análisis predomina, por un lado, un enfoque "personalista", es decir, en su mayoría los estudios se limitan a analizar el papel estructurante y dominante de los personajes principales de la novela y sus relaciones" ( $p .14)$.

Por otro lado, se encuentran lecturas innovadoras sobre este texto, como la elaborada por Sanabria (2016), quien se acerca a la novela desde el concepto freudiano de lo ominoso y analiza la problemática familiar en tanto rompe con los esquemas presentados anteriormente en la literatura costarricense, pues " sin lugar a dudas la primera novela en haber abordado la problemática familiar en la narrativa nacional es La ruta... desde un planteamiento disfuncional como un espacio execrable, ominoso." (p.118).

De ahí que un nuevo acercamiento al texto de Oreamuno sea necesario, pues implica un diálogo entre miradas, ya que ahora no pareciera estar tan en juego lo dicho, sino las nuevas formas de decir. Esta aproximación desde otra práctica significante tan maravillosa como lo es la música, en este caso particular la ópera, involucra la emoción del sonido y su visualización a partir de la puesta en escena como significados en sí mismos.

El compositor costarricense Carlos José Castro, ganador del Grammy por su Concierto del Sol para guitarra y orquesta en 2008 , se ha encargado de dar voz a una obra literaria, a un fragmento de historia, a un discurso silenciado por la sociedad costarricense en tanto no se ajusta al imaginario de identidad construido para cohesionar una masa pretendidamente homogénea llamada "ticos". Para tal efecto, ha trabajado en colaboración con el Teatro Abya Yala, "uno de los grupos de investigación y creación escénica más destacados del istmo" (Campos, 2015, p. 24). Estos elementos que entran en diálogo con la novela de Oreamuno permiten resignificar la carga simbólica del discurso e impregnarla en los cuerpos y en el ambiente circundante por medio del juego entre el sonido, la luz, los colores y los espacios.

\section{(C) $(\Theta \odot \odot$}

La Revista Estudios es editada por la Universidad de Costa Rica y se distribuye bajo una Licencia Creative Commons Atribución-NoComercial-CompartirIgual 3.0 Costa Rica. Para más información envíe un mensaje a revistaestudios.eeg@ucr.ac.cr. 


\section{Diálogo entre la novela y la ópera}

En primer lugar, se abordará el concepto del género musical aplicado a esta producción dentro del contexto nacional. La Dra. Susan Campos en su artículo La Chunga. Una ópera moderna. La performatividad de la obra y la obra como Performance "en el país más feliz del mundo" (2015) indica que "La utilización del término "ópera" como género de "teatro musical", ha ido mutando a través del tiempo... pero en este caso, la propuesta de una "ópera moderna" pareciera dirigir hacia el acto de transgredir un espacio" (p. 25).

La ópera como género musical europeo que se trasplanta y se adapta al espacio costarricense, evidencia una conceptualización novedosa a partir de un imaginario sonoro distinto. Jonathan Sterne (2012) en su texto The Sound Studies Reader, en el primer capítulo titulado "Sonic Imaginations" apunta que

As sonic worlds have changed, so too have the conceptual infrastructures writers have built to behold them. Today, there is a boom in writings on sound by authors in the humanities and social sciences, whose work is distinguished by self-consciousness of its place in a larger interdisciplinary discussion of sound. (p.1).

Por ende, podría plantarse que esta alianza entre el sonido y la imagen se empapa de un discurso que renueva su voz para llegar a un público diferente y ofrecerle un nuevo punto para que desplace su mirada. Así como la Dra. Campos fija su atención en el adjetivo que acompaña al sustantivo ópera, es necesario que se establezca claramente la relación que existe entre el sustantivo ópera y el adjetivo "costarricense", pues este último propone que la ópera responde a una identidad particular delimitada por aspectos geográfico-culturales, específicamente a un contexto latinoamericano mediado por el imaginario del tico, ese sujeto "Pura vida" que se ha proyectado como identidad estandarizada.

\section{(๑) $\odot \odot$}

La Revista Estudios es editada por la Universidad de Costa Rica y se distribuye bajo una Licencia Creative Commons Atribución-NoComercial-CompartirIgual 3.0 Costa Rica. Para más información envíe un mensaje a 
En la novela, Teresa es el eje que interconecta todas las historias y a partir del fluir de su conciencia, retrata a los demás personajes que cohabitan su espacio. Por ejemplo, con Vasco "...mirarte seco para dar una orden terminante respecto a cualquier nimiedad, con tono grave, casi siniestro; o con tono suave, meloso, ofensivo, darte una orden humillante..." (Oreamuno, 1994, p. 50). Si bien es cierto que la ópera mantiene esa introspección por medio de las constantes regresiones de Teresa, pues estas ayudan a estructurar el andamiaje del relato visual, lo cierto es que este "performance" permite a los personajes decirse desde su propia voz, ya que, en este nuevo texto la voz de Teresa no es la mediación que permite acceder a ellos. Estas voces, acompañadas por una selección de ritmos permiten al espectador ubicarse en el espacio latinoamericano, específicamente en Costa Rica como espacio circundante. Si bien la sinopsis que viene en el programa de la ópera (entregado el día 5 de abril del año 2017) plantea la duda sobre la ubicación de la ciudad donde ocurren los hechos, se considera demasiado tradicional leer el texto a la luz de un marco histórico-geográfico que remita directamente a la biografía de la autora, aunque Vallbona (1972) haga hincapié en las referencias que establece la autora entre su vida y su obra, pues una vez que un texto se inserta en el mundo no deberían mediar equivalencias meramente autobiográficas sino que deberían considerarse las contextuales.

La ópera como género musical europeo que se trasplanta y se adapta al espacio costarricense, evidencia una conceptualización novedosa a partir de un imaginario sonoro distinto. De ahí que esta hibridación entre imaginarios sonoros diferentes (ópera permeada de ritmos orientados hacia la identidad latinoamericana) y realidades visuales-escénicas que se amalgaman con un estilo novedoso (lo clásico de la puesta en escena como el vestuario, elementos escenográficos y la iluminación, con el cuerpo humano convirtiéndose en parte de la escenografía) produzcan un efecto de extrañamiento que termina por ubicar al espectador en la más abrumadora realidad, la de la sociedad costarricense negada desde mucho tiempo atrás.

\section{(c) () (-)}

La Revista Estudios es editada por la Universidad de Costa Rica y se distribuye bajo una Licencia Creative Commons Atribución-NoComercial-CompartirIgual 3.0 Costa Rica. Para más información envíe un mensaje a 
Figura \# 1 Cuerpo con parte de la escenografía

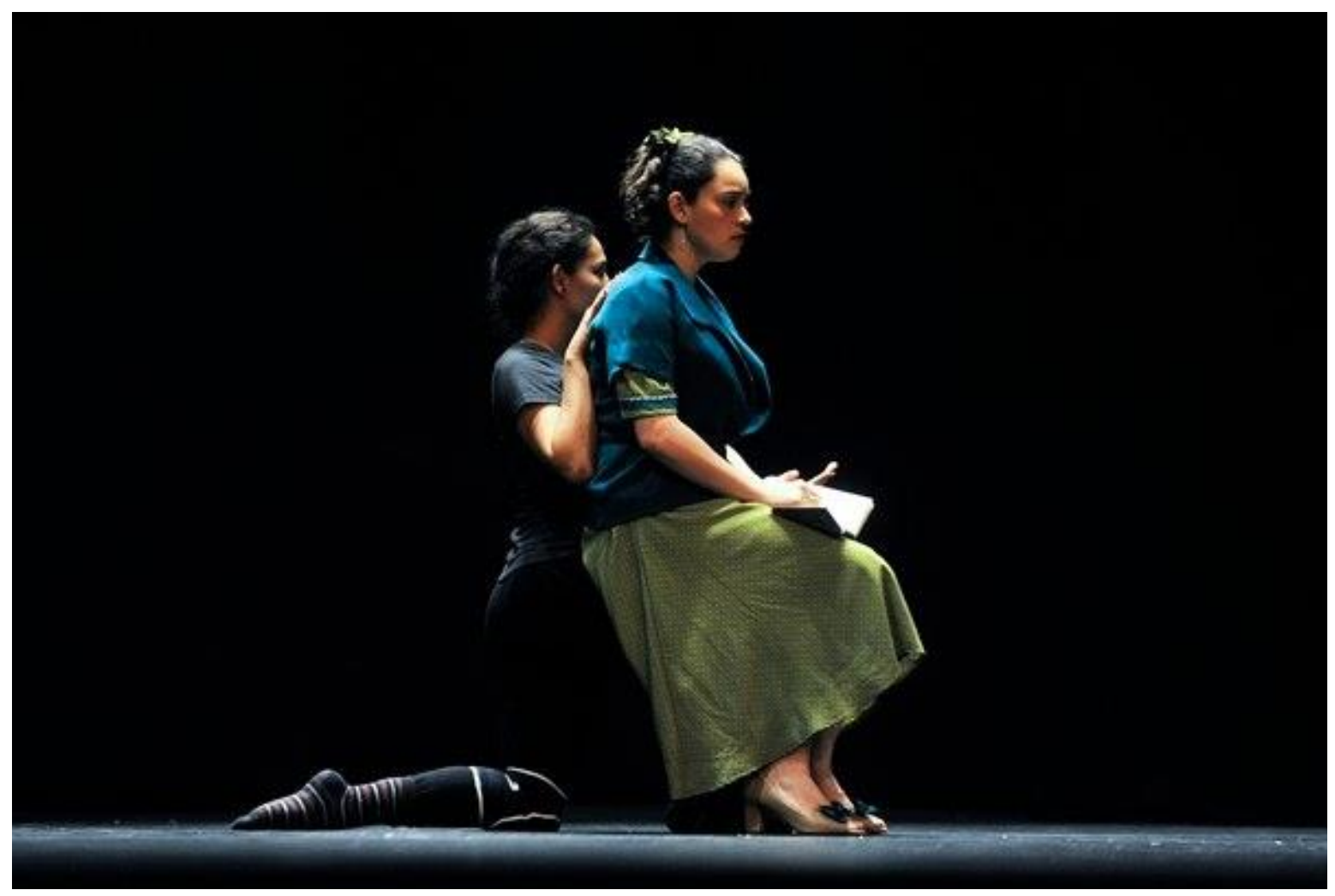

Fuente: Murillo, R. (1 de abril, 2017). Amanda Rodríguez en el papel de Aurora, el amor frustrado de Gabriel. [Fotografía]. Recuperado de:

https://www.nacion.com/viva/cultura/la-ruta-de-su-evasion-canta-a-yolandaoreamuno-en-el-teatro-nacional/BE2WAWQDGFHOZPMJZBXOXEX2II/story/

Si se establecen relaciones entre la música y la construcción de personajes y espacios, se puede evidenciar cómo estos imaginarios sonoros amplifican ese discurso silenciado, cubierto bajo un manto de invisibilidad durante tanto tiempo. El primer personaje por analizar es Vasco Mendoza, típico déspota que exige sumisión disfrazada de "respeto", pero que es incapaz de respetar a quienes están a su alrededor, y en específico a su familia. Este personaje es quien desencadena el proceso de degeneración del núcleo familiar pues funciona como un espejo para

\section{(C) $(\odot \odot$}

La Revista Estudios es editada por la Universidad de Costa Rica y se distribuye bajo una Licencia Creative Commons Atribución-NoComercial-CompartirIgual 3.0 Costa Rica. Para más información envíe un mensaje a revistaestudios.eeg@ucr.ac.cr. 
su hijo mayor Roberto (otro déspota en potencia) y como mecanismo de represión para que no afloren los rasgos humanos de sus otros hijos, Álvaro y Gabriel. Esto se evidencia en el enfrentamiento que tiene con Roberto, cuando este le dice "Por negligencia, por comodidad, por no colocarse como padre ante nosotros y por no abdicar a su posición de déspota," (Oreamuno, 1994, p. 197).

Todas las relaciones de Vasco son conflictivas, desde la opresión ejercida sobre la figura de Teresa, su esposa, hasta el enfrentamiento con Esteban, su antítesis. Vasco, interpretado por Gabriel Morera, de voz "atronadora", refleja la violencia en un sonido que es capaz de opacar, de "tragarse" los demás sonidos y que, sin embargo, carece de claridad, de transparencia para poder proyectar un mensaje articulado. Su voz "infinitamente ruidosa" es una negación del proceso comunicativo, él solo es capaz de ordenar con su voz de trueno que opaca todo con cuanto se topa. La misma incomunicación del texto literario, en este personaje, se proyecta en el espacio sonoro de la ópera.

Figura \# 2 Vasco Mendoza

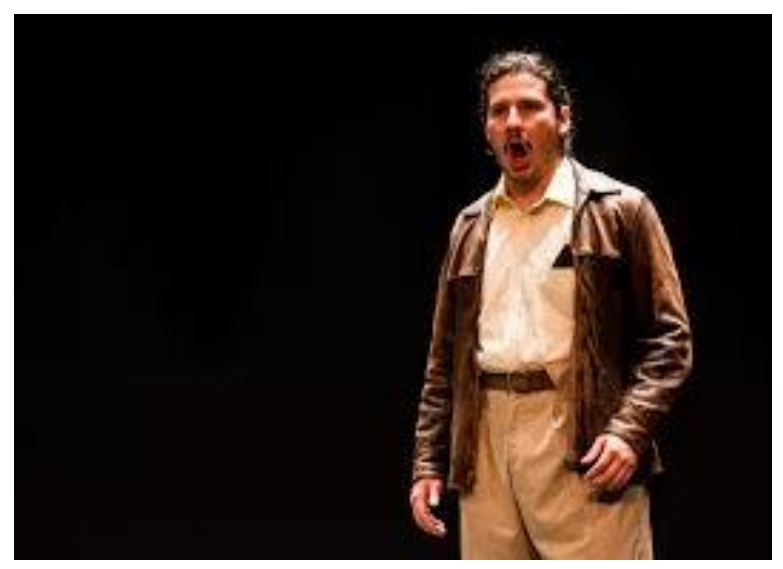

Fuente: Vargas, M. (2017). Sin título. [Fotografía]. Recuperado de: http://www.teatro-abyayala.org/node/202

Por otro lado está Esteban, el amigo de Vasco, interpretado por Andrés Gómez Guzmán, quien constituye la otra "cara de la moneda", de Vasco. Su voz, aun con

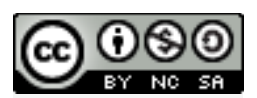

La Revista Estudios es editada por la Universidad de Costa Rica y se distribuye bajo una Licencia Creative Commons Atribución-NoComercial-CompartirIgual 3.0 Costa Rica. Para más información envíe un mensaje a revistaestudios.eeg@ucr.ac.cr. 
su fuerza, evoca la claridad de este personaje, quien aparece en la historia y constituye un remanso para el alma atormentada de Teresa. Su canto devuelve la ilusión a una mujer prisionera del bramido de la tormenta eterna que habita su casa. Como se evidencia en la novela: "Contésteme ahora. ¿Todavía le tiene miedo? No, Esteban. Gracias a usted ya no le tengo miedo." (Oreamuno, 1994, p. 238). Incluso, en la escena del sacrificio se encuentra, en la combinación de la voz y el paisaje sonoro, la emotividad de la entrega, del desprendimiento. Ambos Estébanes imprimen la más dulce ternura y el candor al sacrificio y la entrega, en la novela desde la mirada de Teresa y en la ópera, antes los ojos de los indiscretos espectadores del espacio íntimo de esa casa.

Figura \# 3 Sacrificio de Esteban

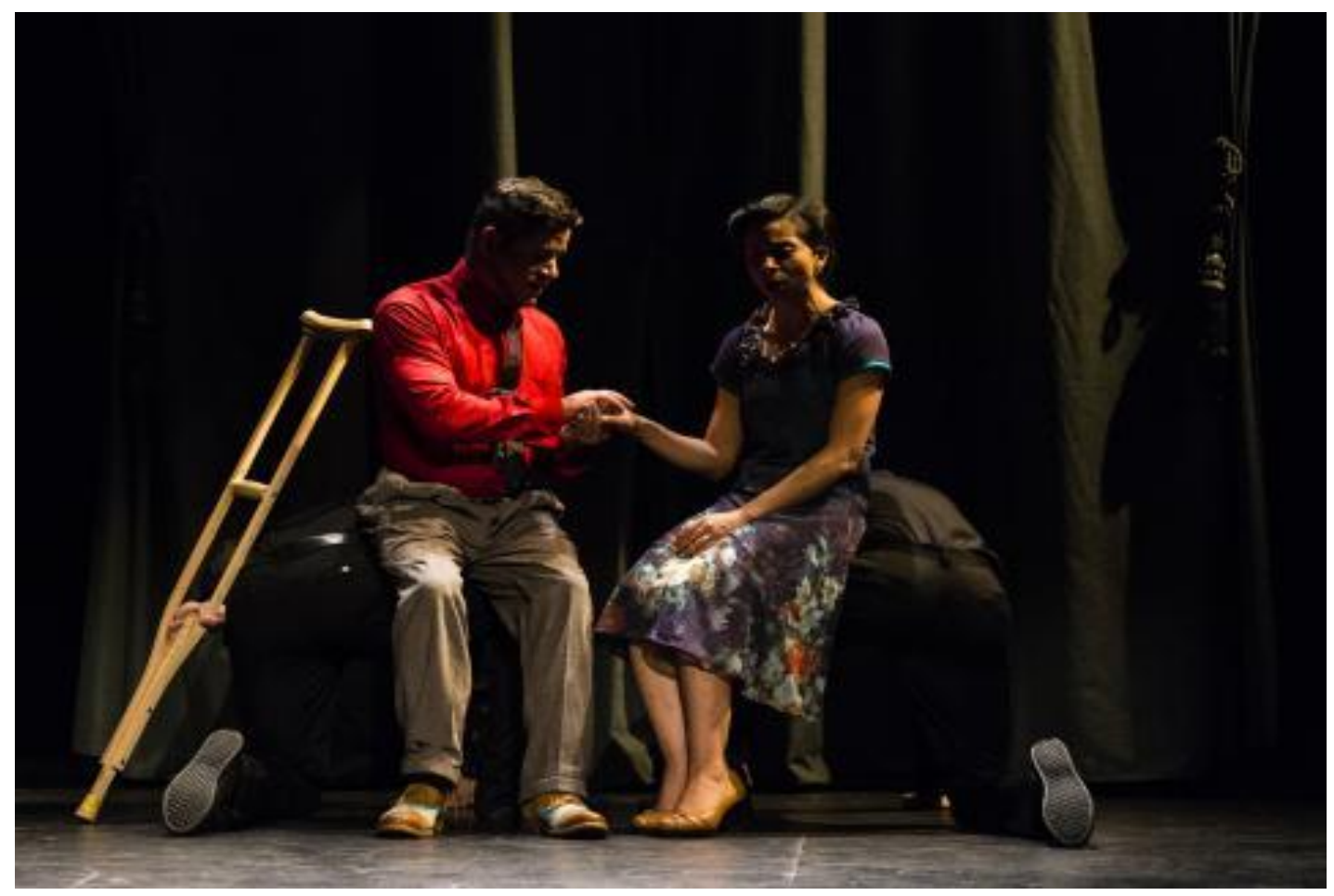

Fuente: Vargas, M. (2017). Sin título. [Fotografía]. Recuperado de: http://www.teatro-abyayala.org/node/202

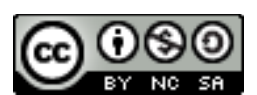

La Revista Estudios es editada por la Universidad de Costa Rica y se distribuye bajo una Licencia Creative Commons Atribución-NoComercial-CompartirIgual 3.0 Costa Rica. Para más información envíe un mensaje a revistaestudios.eeg@ucr.ac.cr. 
Roberto es el hijo mayor, interpretado por Winston Washington, cuya voz es tan solo un murmullo, es la promesa, la potencialidad del déspota que podría llegar a ser, pero todavía no ha aniquilado del todo su conciencia, como su padre; de ahí que pueda existir una oportunidad de cambio. Si bien su voz es opaca y no llega a calar en los escuchas, la dureza de su incipiente discurso permite atisbar la violencia de sus acciones. Como se presenta en la novela: "« yo me voy a estudiar, esto siempre es cuestión de muchas horas, tú sabes que estoy en exámenes; que debo preparar las tesis (...) No me vengas con impertinentes exigencias» (...) «No. Yo iré tal vez después»". (Oreamuno, 1994, pp. 174-175). Este personaje, en ambos textos, debe de sufrir el embate de la realidad con toda su crudeza, para vislumbrar los frutos del camino del desarraigo familiar. Él ha formado una familia, aunque esta sea catalogada por él mismo como un error, pues le dice a su madre: "No estoy enamorado de ella. Ni siquiera me gusta. Se llama Cristina. (...) no permitiré que ella, ni un accidente fortuito y desagradable, ensucien mi honorabilidad y decoro personales."(Oreamuno, 1994, pp. 58-59), y tendrá que enfrentar el sentimiento de pérdida y el duelo por haber asumido el discurso del padre.

Otro de los personajes que responde a un paisaje sonoro particular es Gabriel, el segundo hijo de la familia, interpretado por Miguel Mejía, pues en este se condensan el silencio y el grito desesperado, en el texto literario se construye como un individuo tímido y retraído, pero cuando entra en contacto con un personaje particular (Elena Viales) experimenta la más fuerte desesperación. De igual forma, en el texto escénico se encuentra un Gabriel que naufraga en la angustia y recorre un camino que lo lleva a la muerte como derrota última del ser humano. En la novela se evidencia en el siguiente fragmento: “¡Gabriel! ¡Esto es un suicidio! Sí, pequeña, esto es un suicidio. (...) Estaba tan sereno, tan magnífico, tan profano, como ella no lo vio jamás." (Oreamuno, 1994, p. 332). Su voz sume en la desesperanza al escucha, pues no haya forma alguna de salir de la telaraña de violencia y sinsentido entretejida en el núcleo familiar, la cual se ha

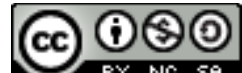

La Revista Estudios es editada por la Universidad de Costa Rica y se distribuye bajo una Licencia Creative Commons Atribución-NoComercial-CompartirIgual 3.0 Costa Rica. Para más información envíe un mensaje a 
expandido a todo su espacio vital. Su voz es el grito desesperado que se sofoca como la llama cuando se consume el oxígeno. Pues él mismo afirma que: "Soy demasiado libre, demasiado viento, agua, lluvia, para que puedas tenerme si no es dormido." (Oreamuno, 1994, p. 333).

Figura \# 4 Muerte de Gabriel

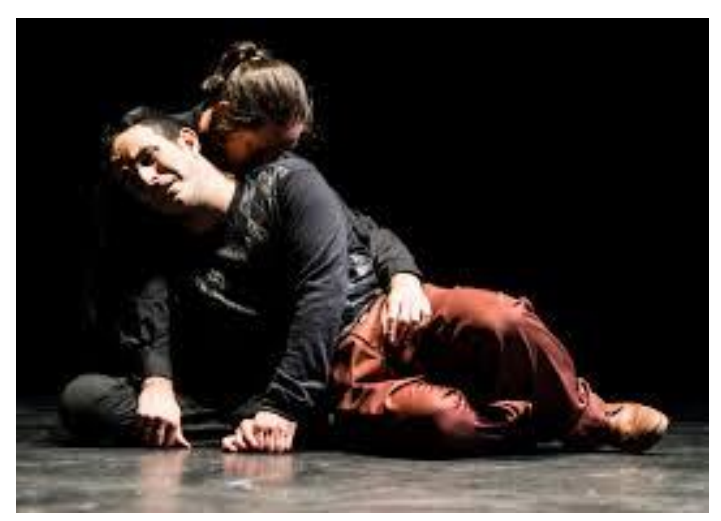

Fuente: Vargas, M. (2017). Sin título. [Fotografía]. Recuperado de: http://www.teatro-abyayala.org/node/202

El último personaje masculino, el hijo menor de la familia Mendoza llamado Álvaro, es la prueba más patente del silencio como violencia ya que, tanto en el texto literario como en el escénico, ha quedado reducido a una sombra muda que deambula por el espacio y se encierra en su misma corporeidad. En el texto literario se plantea el onanismo que ha desarrollado este personaje a partir de su encierro en sí mismo. Como se aprecia en el siguiente fragmento: "miran el pantalón caído de Álvaro; una de sus manos temblorosas oprimiendo algo que vuelve a enrojecerla. El periódico que la otra mano sostiene está con las letras al revés." (Oreamuno, 1994, p.144). Y de cierta manera, proyecta la orfandad en que lo sume la incomunicación por el abandono de la figura paterna.

\section{(C) $(0 \otimes)$}

La Revista Estudios es editada por la Universidad de Costa Rica y se distribuye bajo una Licencia Creative Commons Atribución-NoComercial-CompartirIgual 3.0 Costa Rica. Para más información envíe un mensaje a revistaestudios.eeg@ucr.ac.cr. 
Figura \# 5 Silencio de Álvaro, hijo menor de la familia Mendoza

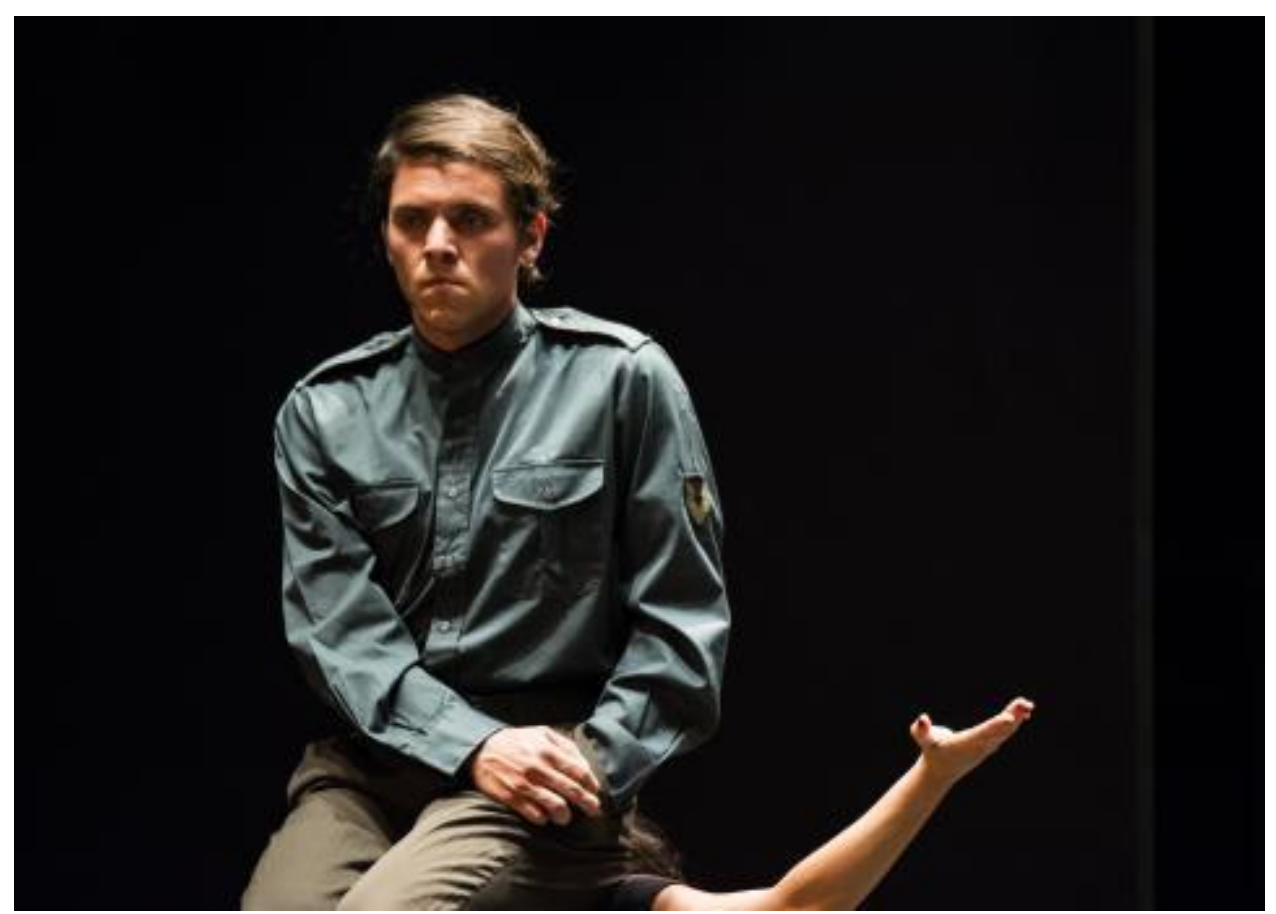

Fuente: Vargas, M. (2017). Sin título. [Fotografía]. Recuperado de: http://www.teatro-abyayala.org/node/202

El último personaje que queda por analizar en la familia Mendoza es Teresa, interpretada por Isabel Guzmán Payés, la figura femenina que articula este espacio de desencuentros. Ella es el reflejo de la mansedumbre, pues encarna la sumisión absoluta ante la brutalidad de su esposo y la insensibilidad de sus hijos. Tanto en el texto como en la ópera ella es víctima de diversos tipos de violencia, que van desde la física hasta la psicológica. Tal vez, la manifestación más corrosiva de esta sea el abrumador silencio que la envuelve, lo cual se evidencia en la novela: "¿Qué hablarán los hombres cuando conversan para ellos? Ha de ser bonito tener con quien hablar, tener quien lo escuche a uno." (Oreamuno, 1994, p.67).

\section{(c) $10(0$}

La Revista Estudios es editada por la Universidad de Costa Rica y se distribuye bajo una Licencia Creative Commons Atribución-NoComercial-CompartirIgual 3.0 Costa Rica. Para más información envíe un mensaje a revistaestudios.eeg@ucr.ac.cr. 
Figura \# 6 Ataque de vasco en contra de Teresa

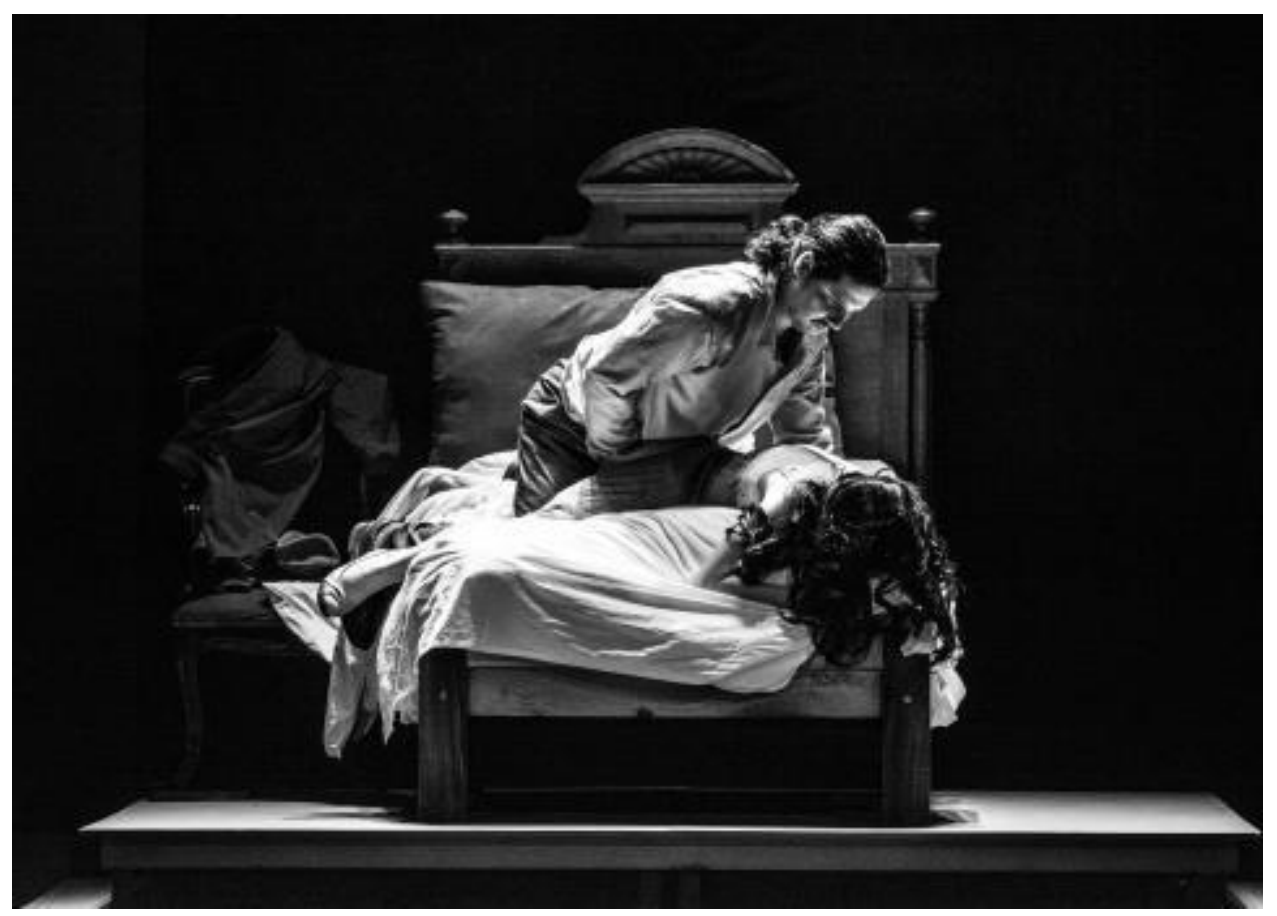

Fuente: Vargas, M. (2017). Sin título. [Fotografía]. Recuperado de: http://www.teatro-abyayala.org/node/202

Su identidad está en función de otros pues ha sido disminuida poco a poco por la falta de interacción familiar. $Y$ aunque en la puesta en escena no se encarga de "decir" a los demás, sí los une a través de sus recuerdos, su presencia y su recuerdo. La voz de Teresa es capaz de transportar al oyente al dolor más profundo y luego, en sus retrospecciones, a la candidez más embelesadora. Ese paisaje sonoro creado por la voz de la intérprete es capaz de transportar a los espectadores a la realidad de una mujer cuya personalidad le ha sido arrebata por la violencia y la incomunicación, a tal punto, que ella misma se excluye de su propio espacio; es decir, su hogar. Como se evidencia en ese fluir de su conciencia: "¿Ya no cantas, Teresa, verdad que ya no cantas? Para qué vas a hacerlo si tu música estorba el silencio de la casa. Y ya no ríes. Cansa reír sola." (Oreamuno, 1994, p. 51).

\section{(C) $(1)$}

La Revista Estudios es editada por la Universidad de Costa Rica y se distribuye bajo una Licencia Creative Commons Atribución-NoComercial-Compartirlgual 3.0 Costa Rica. Para más información envíe un mensaje a revistaestudios.eeg@ucr.ac.cr. 


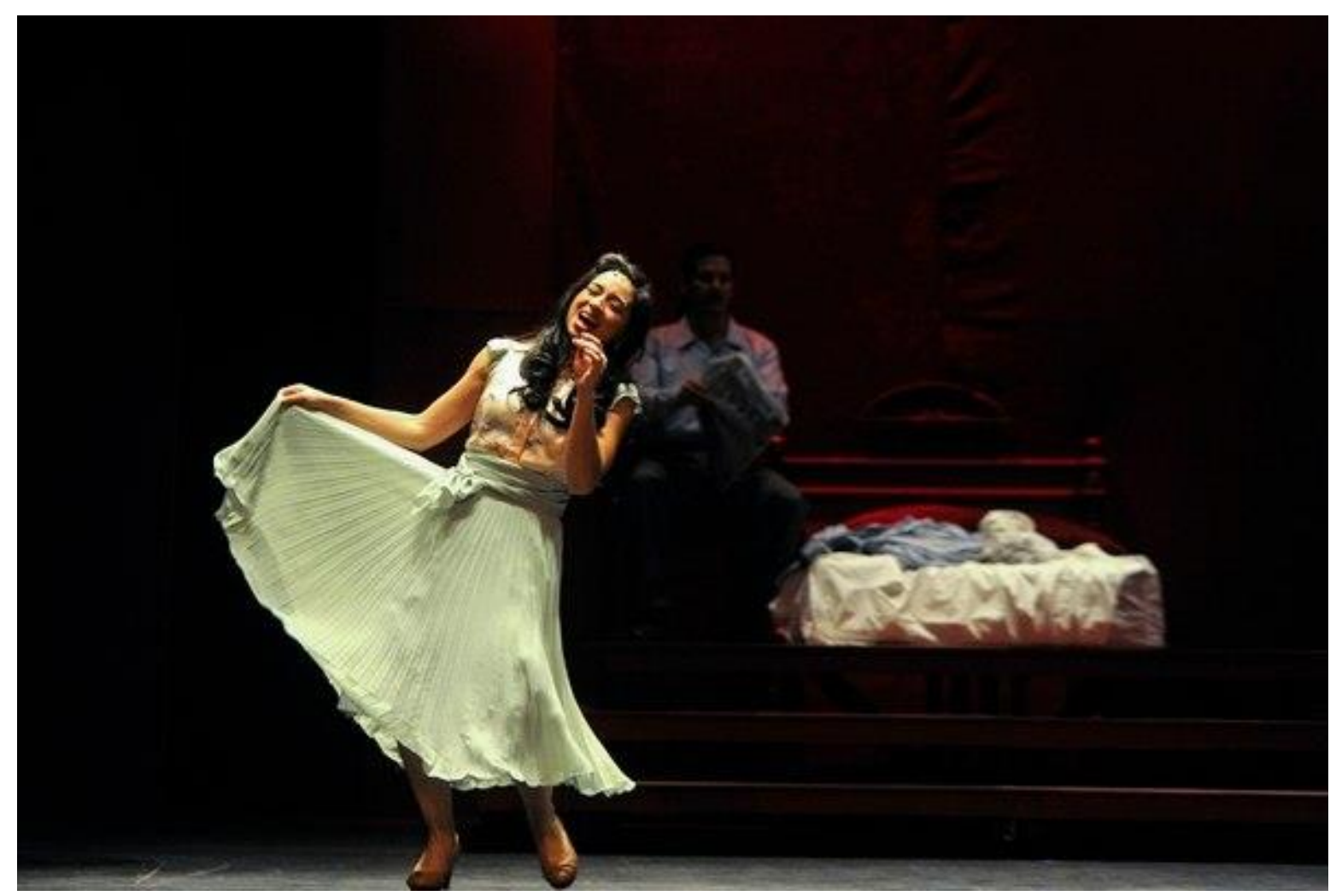

Fuente: [Fotografía sin título de descripción del trabajo] (3 de abril, 2017).Recuperado de: https://www.nacion.com/viva/musica/critica-de-operaevasiones-y evasores/GWIYNQDASRB3ZKERRROMQGLV7I/story/

Esa tensión que se presenta entre el silencio y la voz evidencia una fuerte crítica hacia la sociedad de la época, que establecía una visión alienada de lo femenino. Rebeca Quirós Bonilla (2007), en su artículo "La Mujer, lo Femenino y lo Arquetípico en la Novela La Ruta de su Evasión de Yolanda Oreamuno" propone lo siguiente: "Mujer consciente, comprometida e introspectiva, la escritora Yolanda Oreamuno ofrece todos los elementos para un análisis de su visión de lo femenino, de su visión de lo humano y, por lo tanto, de lo arquetípico" (p.64). Aquí se plantea que lo femenino está en consonancia con lo humano, con la voz, la decisión, el ser y la identidad.

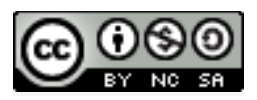

La Revista Estudios es editada por la Universidad de Costa Rica y se distribuye bajo una Licencia Creative Commons Atribución-NoComercial-CompartirIgual 3.0 Costa Rica. Para más información envíe un mensaje a revistaestudios.eeg@ucr.ac.cr. 
Si bien ya se abordó la construcción de Teresa de Mendoza y se dijo que ella se va de-construyendo poco a poco en favor de esos otros (propios-familia) que cohabitan con ella. También es necesario mencionar que este es un proceso consciente, en el cual ella cede el espacio a la masculinidad y se autoexilia en el deterioro físico y mental que la llevará, en última instancia, a la aceptación de su muerte como única liberación posible. Como se observa en la novela: "estoy muerta ya, colocan algo bajo mi cuerpo, es el ataúd, ya estoy muerta, ya me ponen allí,..." (Oreamuno, 1994, p.99).

Figura \# 8 Teresa en agonía

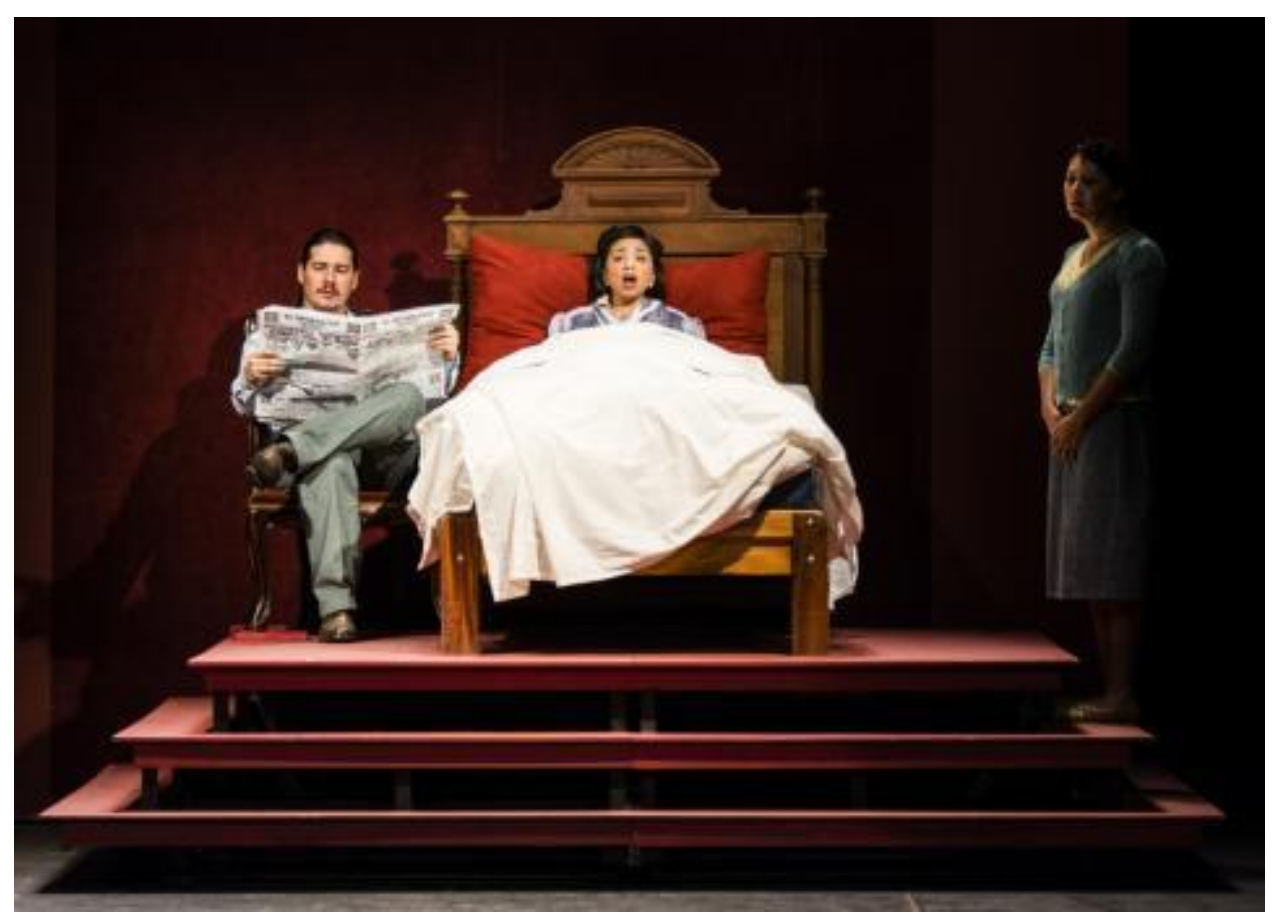

Fuente: Vargas, M. (2017). Sin título. [Fotografía]. Recuperado de: http://www.teatro-abyayala.org/node/202

De igual forma, en otros personajes femeninos se aprecian características similares. Por ejemplo Cristina, la esposa de Roberto, interpretada por Adriana Víquez, en quien se repite la idea del sacrificio por la familia. Su puesta en escena del personaje proyecta la voz de la juventud ilusionada a partir del hecho de

\section{(๑) $\odot \odot$}

La Revista Estudios es editada por la Universidad de Costa Rica y se distribuye bajo una Licencia Creative Commons Atribución-NoComercial-CompartirIgual 3.0 Costa Rica. Para más información envíe un mensaje a revistaestudios.eeg@ucr.ac.cr. 
Revista Estudios, (39), 2019.

Diciembre 2018-Mayo 2019

ISSN 1659-3316

conformar una familia, promesa de un futuro próspero (desde la construcción creada para las mujeres), pues esta debe ser su mayor realización. Sin embargo, conforme avanza la obra, este personaje se desencanta de este patrón y entra en crisis con su identidad femenina, pues se revela ante la indiferencia de su esposo y va sola al hospital, de donde no regresarán a casa ni ella ni su hijo, Como se aprecia en la novela: "Cristina siente deseos de reír, pero no puede. La idea del hospital, del hijo, y sobre todo, las duras palabras de Roberto al despedirla, hacen que esa risa se vuelva un nudo de dolor en su garganta. Ella irá sola.". (Oreamuno, 1994, p. 171). Su hijo se convierte en una promesa de redención del ámbito familiar que se pierde, tragado por un río de sangre, en el silencio y el abandono.

Figura \# 9 Cristina muere desangrada
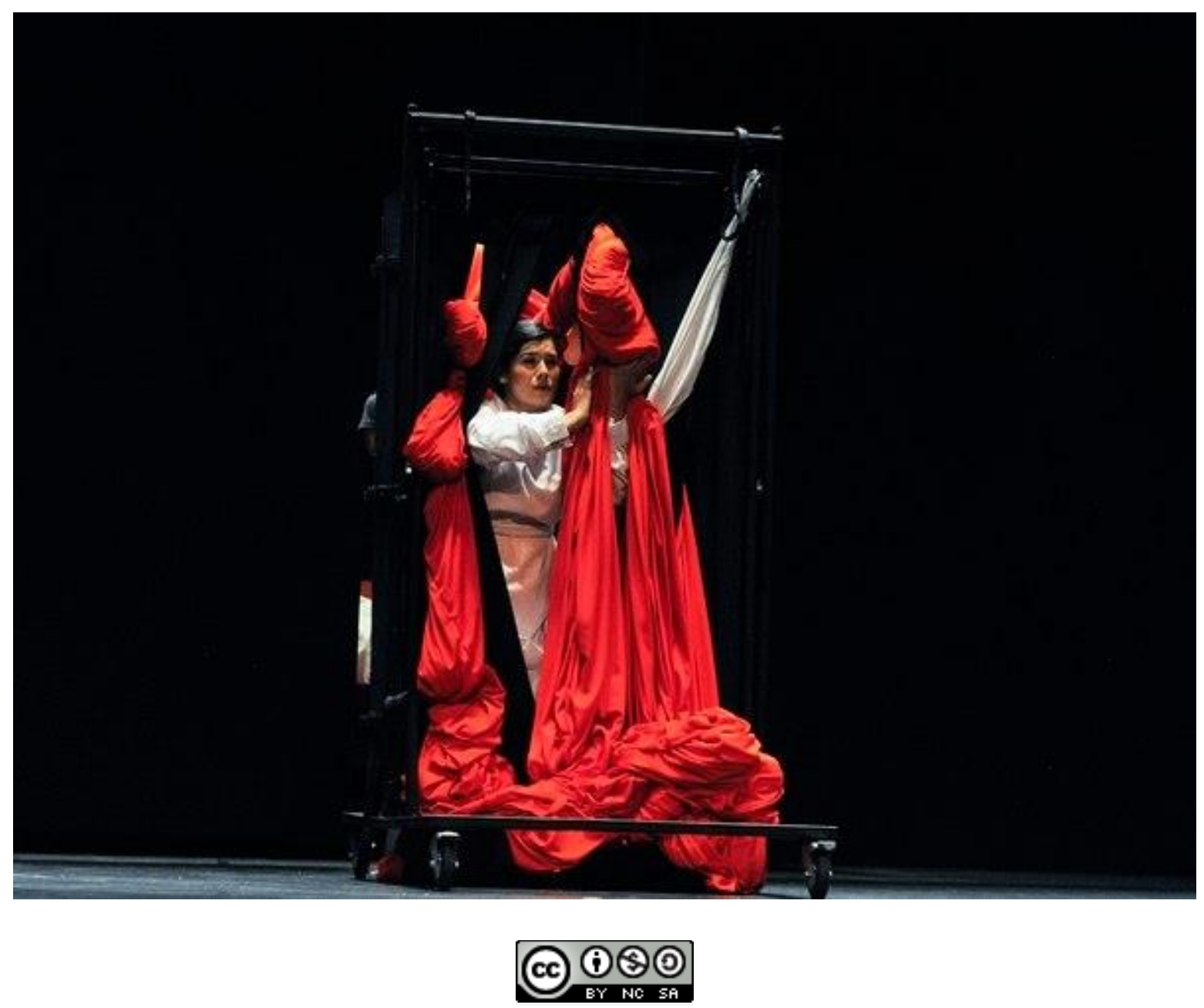

La Revista Estudios es editada por la Universidad de Costa Rica y se distribuye bajo una Licencia Creative Commons Atribución-NoComercial-CompartirIgual 3.0 Costa Rica. Para más información envíe un mensaje a revistaestudios.eeg@ucr.ac.cr. 
Fuente: Murillo, R. (1 de abril, 2017). Adriana Víquez interpreta a Cristina, esposa del hijo mayor de los Mendoza. [Fotografía]. Recuperado de:

https://www.nacion.com/viva/cultura/la-ruta-de-su-evasion-canta-a-yolandaoreamuno-en-el-teatro-nacional/BE2WAWQDGFHOZPMJZBXOXEX2II/story/

Por otro lado, existen otros personajes que hacen un intento por quebrar ese molde social y liberarse de ese intrincado rompecabezas que les asigna un espacio inmutable, al cual están condenadas, para poder ser parte del entramado conocido como sociedad. El primero de ellos es Aurora, la enamorada de Gabriel, interpretada por Amanda Rodríguez. Este personaje evidencia una evolución en ese constructo social denominado identidad femenina, pues aunque en el texto literario se le plantea, en una primera instancia, como una tonta; ella es la única que se enfrenta, poco a poco, con ese espacio de marginación para buscar la libertad.

Aurora es el nuevo sol que sale después de la tempestad (espacio simbólico del conflicto que lleva a la muerte) que acaba con la casa Mendoza. En la puesta en escena es visible esa evolución porque de estar supeditada a la voluntad de Gabriel (un hombre que no solo no la ama, sino que le fastidia su presencia) pasa a salir del encierro que significaba la presencia del "amado" y aventurarse en un mundo de posibilidades. De igual forma se aprecia en la novela: "« ¡Pero si yo estoy libre! (...) Yo amé a un muerto, pero ahora amo la vida." (Oreamuno, 1994, p.360). Aunque, la decisión se da gracias a la muerte de este, es rescatable que ella no se quede en la inercia. Como se observa en el fragmento: "Después miró el cuerpo de Gabriel. No tenía ninguna pena, como si nunca el amor la hubiera poseído, como si no hubiera sido víctima del terror" (Oreamuno, 1994, p. 362).

\section{(c) (i) (2) (2)}

La Revista Estudios es editada por la Universidad de Costa Rica y se distribuye bajo una Licencia Creative Commons Atribución-NoComercial-CompartirIgual 3.0 Costa Rica. Para más información envíe un mensaje a 
Figura \# 10 Aurora, enamorada de Gabriel

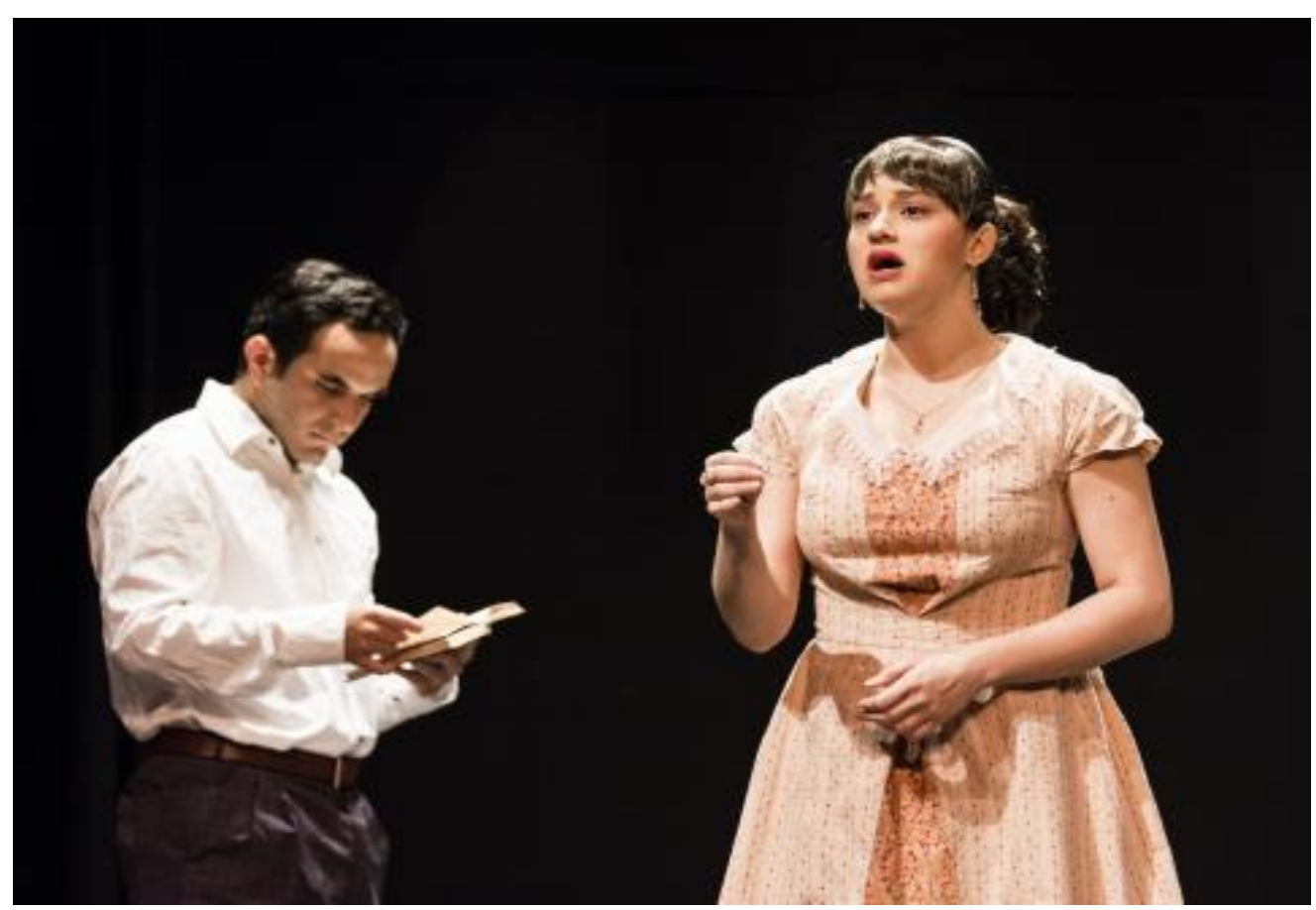

Fuente: Vargas, M. (2017). Sin título. [Fotografía]. Recuperado de: http://www.teatro-abyayala.org/node/202

Y por último está Elena Viales, la amante de Gabriel interpretada por Keren Padilla. Este personaje, a simple vista, se propone como subversivo ya que ha sido formada por su padre para rechazar el rol femenino tradicional. Ella es caprichosa y obstinada, absolutamente mordaz y manipuladora. Su padre la ha criado a partir de su tesis de la "libertad de la mujer", por lo cual, era inconcebible verse atada a un hombre. Sin embargo, al entrar en contacto con Gabriel se da en ella un conflicto que la lleva a cuestionarse qué tan real es su libertad.

\section{(a) $(\oplus \circ$}

La Revista Estudios es editada por la Universidad de Costa Rica y se distribuye bajo una Licencia Creative Commons Atribución-NoComercial-CompartirIgual 3.0 Costa Rica. Para más información envíe un mensaje a revistaestudios.eeg@ucr.ac.cr. 
Figura\# 11 Elena, amante de Gabriel, durante la autopsia

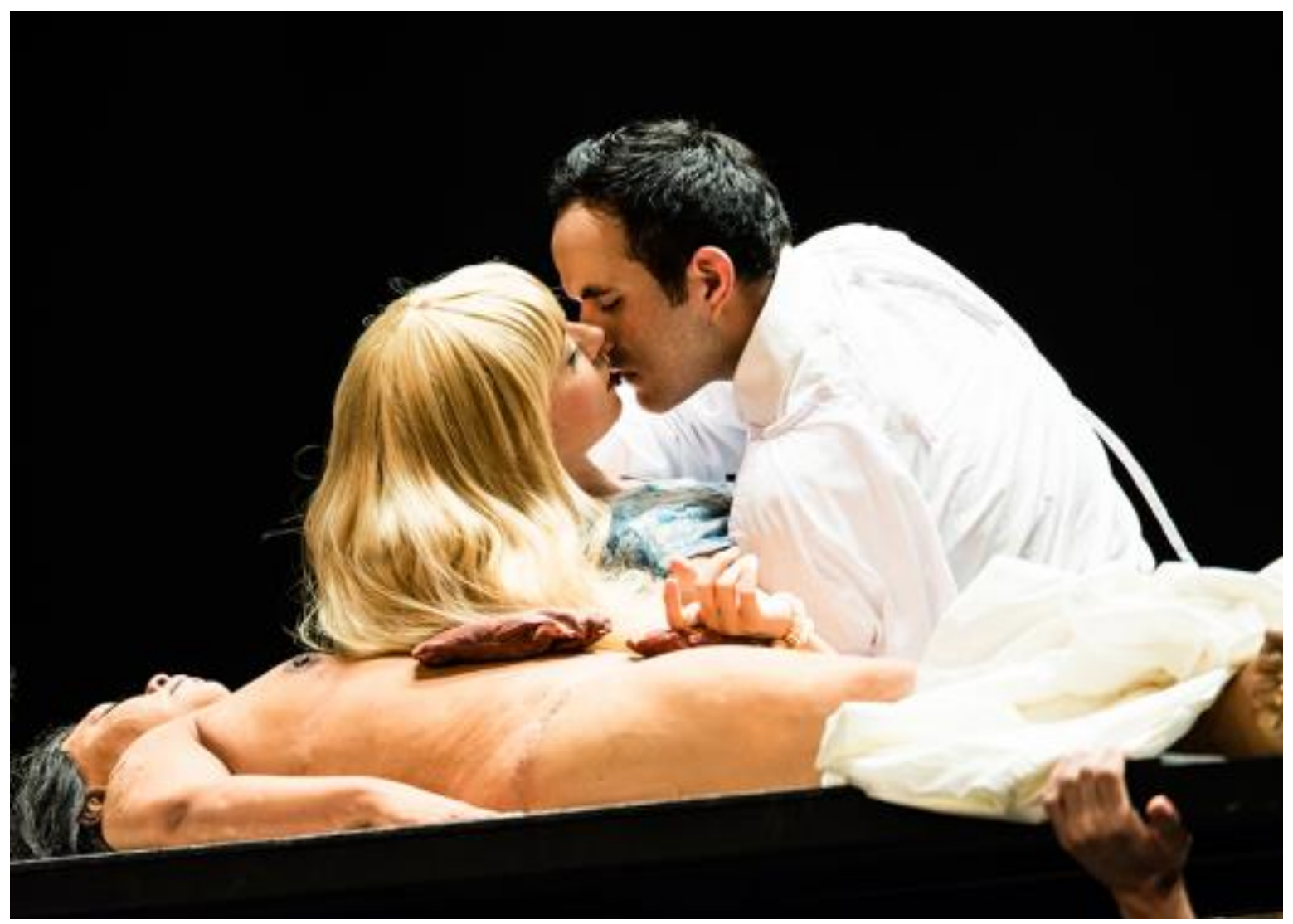

Fuente: [Fotografía sin título de descripción del trabajo] (2017).Recuperado de: https://kerenpadilla.com/elena-viales/

Esta construcción contestataria esconde en el fondo un ser violentado a quien se le impide escoger. Situación que provoca un conflicto en Elena, pues la enfrenta con el deber ser impuesto por la sociedad (su padre) y su deseo (seguir con Gabriel). En la novela es patente la angustia de Elena al pensar en contrariar a su padre y la respuesta burlona y desautorizadora que este le daría: "Como espero que no te preocupes por tan miserable accidente, dime si prefieres un cambio de automóvil, un coscorrón o un viaje. ¡Es maravilloso esto de tener una hija de tu fragilidad! (...) «¿Pero no estás enamorada?" (Oreamuno, 1994, p 205). También es necesario reconocer que la construcción del personaje, su puesta en escena y

\section{(C) $(\Theta \odot$}

La Revista Estudios es editada por la Universidad de Costa Rica y se distribuye bajo una Licencia Creative Commons Atribución-NoComercial-CompartirIgual 3.0 Costa Rica. Para más información envíe un mensaje a revistaestudios.eeg@ucr.ac.cr. 
la amalgama perfecta entre el discurso y la potencia de su voz calan hasta lo más profundo y envuelven al oyente en ese conflicto existencial.

Todos estos elementos tan eficientemente cohesionados develan la verdadera interdisciplinariedad de los paisajes sonoros que se apoyan en múltiples componentes y logran ese maravilloso efecto sinestésico del silencio hecho voz, canto, grito, llanto, risa y susurro. A propósito de la reflexión anterior, se considera pertinente darle la palabra otra vez a Sterne (2012).

Sound studies is a name for the interdisciplinary ferment in the human sciences that takes sound as its analytical point of departure or arrival. By analyzing both sonic practices and the discourses and institutions that describe them, it redescribes what sound does in the human world, and what humans do in the sonic world. (I say it redescribes rather than describes because good scholarship always goes beyond the corrirrionsense categories used in everyday descriptive language-it tells us what we don't already know). (p.2).

\section{Consideraciones finales}

La ópera costarricense La Ruta de su Evasión renueva la voz discursiva de Yolanda Oreamuno y permite un acercamiento a esta pieza de la literatura nacional, desposeída de una presencia real en los anales de nuestra literatura, en tanto ha sido abordada desde ópticas muy restringidas por la crítica. Pues a diferencia del texto, la ópera presenta algunas resonancias, en la prensa nacional, orientadas al discurso y no meramente a la forma.

En La ruta de su evasión (1948), Yolanda Oreamuno escribe sobre una casa con cimientos frágiles: Vasco, un padre opresor; Teresa, una madre suprimida; y Roberto, Gabriel y Álvaro, tres hijos toscos y confundidos por la falta de amor. (Díaz, 2017, párr. 2-3).

\section{(c) (i) (2)}

La Revista Estudios es editada por la Universidad de Costa Rica y se distribuye bajo una Licencia Creative Commons Atribución-NoComercial-CompartirIgual 3.0 Costa Rica. Para más información envíe un mensaje a 
Aunque la crítica es bastante escueta, se considera importante retomar estas maravillosas manifestaciones de nuestra cultura literaria y vincularlas con otras prácticas significantes, con el fin de que lleguen a otros espacios y susciten la curiosidad de más costarricenses para que se acerquen a los elementos constitutivos de nuestra historia artística.

Para finalizar esta breve reflexión, se considera necesario una revisión del apartado, inserto en el programa, titulado Palabra Enamorada de Jacques Sagot, pues es tremendamente llamativo que esta palabra mediada por la violencia, el enfrentamiento y la sumisión se catalogue como "enamorada". Ella estuvo sumida en el silencio de la crítica, culpabilizada por los "pecados" achacados a su autora y luego fue víctima de lecturas banales que buscaban en ella meras referencias autobiográficas, sin ir más allá, a su riqueza simbólica.

Incluso, Sagot habla de "amor" lo cual se considera ambiguo, pues la pregunta que surge es ¿amada por quién? Si es una generalización; es decir, los ticos, ¿por qué la mayoría de nuestros estudiantes no saben quién es? Si fuese en el ámbito académico, ¿será que ella, su voz, su palabra, su vida está reservada para unos cuantos elegidos? Al no saber en específico al cuál nosotros se alude, es dudosa la validez de ese amor.

También es interesante el énfasis que da al discurso de la belleza de la forma (el cual no se desmerita de ninguna manera), pero sorprende que lo más profundo, lo más conmovedor, lo que nos hermana en la humanidad: el discurso, ya sea político, social, psicológico, de género, entre otros; ocupe un plano secundario pues apenas y se menciona. Esto implicaría que esta autora solo puede captar a aquellos que tengan ese refinado gusto que da la erudición. En fin, existen múltiples maneras de acercarse a un texto, a un autor, a una visión de mundo. Tal vez lo más importante es prestar atención al entorno, al paisaje que rodea a ese elemento para indicar que esa mirada responde al color del cristal con que se mire.

\section{(c) (†) (-)}

La Revista Estudios es editada por la Universidad de Costa Rica y se distribuye bajo una Licencia Creative Commons Atribución-NoComercial-CompartirIgual 3.0 Costa Rica. Para más información envíe un mensaje a revistaestudios.eeg@ucr.ac.cr. 
A partir de lo anterior, es tremendamente rescatable que la música y el teatro se unan para reivindicar la literatura, en particular este tipo de literatura que se ha dejado de lado como elemento de nuestra cultura nacional, pues este tipo de textos son elogiados desde las miradas distantes del pasado, y por aspectos meramente formales. En este tipo de miradas anquilosadas La Ruta de su Evasión se vuelve también nuestra evasión de todo aquello que nos recuerde nuestra humanidad, nuestros conflictos, esa sombra presente en todo ser humano, salvo en los ticos "Pura Vida", claro está.

\section{Referencias}

Abya Yala | Asociación Cultural para las Artes Escénicas (2017). La Ruta de su Evasión (2017). Recuperado de: http://www.teatro-abyayala.org/node/202

Arrillaga, M. (1989). “Atisbos feministas en La ruta de su evasión de Yolanda Oreamuno". En Caribbean Studies, 22, (3/4), pp. 47-56. Recuperado de: http://www.scriptorium.una.ac.cr/index.php/otros-estudios-sobre-yolandaoreamuno?download=69:atisbosfeministasenlaruta-arrillaga.

Campos, S. (2015). “La Chunga. Una ópera moderna. La performatividad de la obra y la obra como Performance "en el país más feliz del mundo" ". En: Escena. Revista de las artes. 74, (2), pp. 21-36. Recuperado de: https://revista.inie.ucr.ac.cr/index.php/escena/article/view/22579

Díaz Zeledón, N. (2017, 1 de abril). La ruta de su evasión' canta a Yolanda Oreamuno en el Teatro Nacional. La Nación. Recuperado de: https://www.nacion.com/viva/cultura/la-ruta-de-su-evasion-canta-a-yolandaoreamuno-en-el-teatronacional/BE2WAWQDGFHOZPMJZBXOXEX2II/story/

Mackenback, W. (2007). YO o las trampas de la biografía. En: Revista de Filología y Lingüística, 33, (2), pp. 11-22. Recuperado de: https://revistas.ucr.ac.cr/index.php/filyling/article/view/1733/0 
Revista Estudios, (39), 2019.

Diciembre 2018-Mayo 2019

ISSN 1659-3316

Salazar Horr Marlene

Núñez Moya, J, Zapparoli Zecca, M. (2007). El discurso patriarcal en La ruta de su evasión de Yolanda Oreamuno: Una lectura de la otredad a través de la polifonía Bajtiniana. En Revista PRAXIS (60), 9-37. Recuperado de: http://www.revistas.una.ac.cr/index.php/praxis/article/view/5084

Oreamuno, Y. (1994). La Ruta de su Evasión. EDUCA. San José, Costa Rica.

Padilla, K. (2017). Cantante Lírica - Mezzo Soprano Keren Padilla. Recuperado de: https://kerenpadilla.com/elena-viales/

Quirós, R. (2008). "La mujer, lo femenino y lo arquetípico en la novela La ruta de su evasión de Yolanda Oreamuno". En Reflexiones. Revista Facultad de Ciencias Sociales. 87, (1), pp. 63-72. Recuperado de: https://revistas.ucr.ac.cr/index.php/reflexiones/article/view/11485

[Crítica de ópera: Evasiones y evasores]. (2017, 3 de abril). La Nación. Recuperado de: https://www.nacion.com/viva/musica/critica-de-operaevasiones-y-evasores/GWIYNQDASRB3ZKERRROMQGLV7I/story/

Sanabria, C. (2016). "La representación del espacio familiar como ominoso en la literatura costarricense: de La ruta de su evasión a Larga noche hacia mi madre". En: Revista de Filología y Lingüística, 42, Número Especial, pp.117-127.

Recuperado

de: https://revistas.ucr.ac.cr/index.php/filyling/article/view/26469

Sterne, J. (2012). The Sound Studies Reader. Recuperado de: https://pzacad.pitzer.edu/ mma/.../Sterne-SoundStudiesReader.pdf

Vallbona, R. (1972). "Yolanda Oreamuno: El estigma del escritor". En: Cuadernos Hispanoamericanos, (270) (diciembre 1972), pp. 474-500. Recuperado de: http://www.cervantesvirtual.com/obra/yolanda-oreamuno-el-estigma-delescritor/

\section{(c) (i) (2)}

La Revista Estudios es editada por la Universidad de Costa Rica y se distribuye bajo una Licencia Creative Commons Atribución-NoComercial-Compartirlgual 3.0 Costa Rica. Para más información envíe un mensaje a revistaestudios.eeg@ucr.ac.cr. 